\title{
SUBJETIVIDADE E VERDADE NO ÚLTIMO FOUCAULT
}

Cesar CANDIOTTO ${ }^{1}$

- RESUMO: A constituição do sujeito na investigação do último Foucault geralmente é conhecida pela perspectiva de sua estética da existência. Tal abordagem deve-se sobremaneira à leitura dos dois últimos volumes de Histoire de la sexualité (1984). No entanto, o presente artigo aponta que nos cursos no Collège de France intitulados Subjectivité et verité (1981) e L'herméneutique du sujet (1982) outra leitura pode ser elaborada. A relação entre subjetividade e verdade evidencia-se como central em seu pensamento e seus desdobramentos são apresentados a partir das diferenças estabelecidas entre filosofia e espiritualidade, das articulações entre cuidado de si e conhecimento de si, conhecimentos úteis e inúteis, cuidado de si e conversão a si, ascese e verdade.

- PALAVRAS-CHAVE: Subjetividade, Verdade, Ascese, Conhecimento de si, Cuidado de si.

\section{Introdução}

O pensamento do último Foucault tem sido freqüentemente caracterizado pelo seu viés estético, precisamente, como estética da existência. A constituição do sujeito ético é pensada como efeito das técnicas de si que objetivam a condução de uma vida bela. Essa identificação entre o bom e o belo, entre o ético e o estético deriva naturalmente dos gregos. Pensadores como Platão, Xenofonte e Epicuro afirmam ser a ética condição da estética, o belo sendo alcançado como conseqüência da busca pelo bem. Ocorre que

1 É Doutor em Filosofia pela Pontifícia Universidade Católica de São Paulo e professor do Departamento de Filosofia e do Programa de Pós-Graduação da Pontifícia Universidade Católica do Paraná. 
no imaginário individual e coletivo dos modernos inexiste a dependência entre ética e estética. Esta última é pensada como realidade autônoma, descomprometida em relação ao bem e ao mal. Daí a dificuldade, apontada por Pierre Hadot, de tratar da constituição do sujeito ético a partir do critério da estética da existência, como quer Foucault. Para Hadot (2002a, p.308), em lugar de apontar a constituição antiga do sujeito pela clave da cultura de si na qual a estética é relevada, melhor seria abordá-la em termos de transformação, transfiguração, "ultrapassagem de si".

No presente ensaio, sustenta-se que Foucault não ignora ser a transformação da maneira de viver algo fundamental para a constituição antiga (e um desafio também para os modernos). Além disso, a observação de Hadot a respeito de Foucault seria totalmente desnecessária se ele acentuasse na última etapa do pensamento de Foucault a problematização da subjetividade e sua relação com a verdade. Subjetividade que aqui se refere não à identificação com o sujeito como categoria ontologicamente invariável, mas a modos de agir, a processos de subjetivação modificáveis e plurais. Nesse sentido é que também Foucault entende a constituição do sujeito antigo como ultrapassagem de si.

Além de diversas manifestações nos Dits et Écrits, volume IV, a relação entre subjetividade e verdade é problematizada no curso Subjectivité et verité (1981) e L'herméneutique du sujet (1982) e difere da maneira como tem sido tradicionalmente tratada pela filosofia.

$\mathrm{Na}$ perspectiva filosófica tradicional, de Platão a Kant, passando por Descartes, a articulação entre subjetividade e verdade parte das seguintes questões: como e em que condições é possível conhecer a verdade? Como é alcançável o conhecimento legítimo a partir da experiência do sujeito cognoscente? De que modo quem realiza tal experiência reconhece que se trata de conhecimento verdadeiro? Em suma, o problema filosófico da articulação entre subjetividade e verdade postula ser inaceitável a existência de verdade sem que a preceda o sujeito puro a partir do qual ela é considerada verdadeira.

Michel Foucault procura tomar distância de tais questões, abordando a articulação entre subjetividade e verdade pelo viés histórico. Nesse caso, as perguntas passam a ser outras. Para começar, que relação o sujeito estabelece consigo a partir de verdades que culturalmente lhe são atribuídas? Tal interrogante parte do fato de que em qualquer cultura há enunciações sobre o sujeito que, independentemente de seus valores de verdade, funcionam, são admitidas e circulam como se fossem verdadeiras. Daí outra questão: considerando o que são tais discursos em seu conteúdo e em sua forma, levando em conta os laços entre obrigações de verdade e a constituição de subjetividades, que experiência os seres humanos fazem de si próprios? Decorre que em vez de examinar as condições e possibilidades da verdade 
para um sujeito em geral, Michel Foucault procura saber quais são os efeitos de subjetivação a partir da própria existência de discursos que pretendem dizer uma verdade para o sujeito.

Um sobrevôo pela articulação entre subjetividade e verdade na investigação anterior de Foucault possibilita estabelecer diferenças significativas em relação à perspectiva filosófica, tal como ele a entende. Quando aborda jogos teóricos e científicos, ele trata das práticas discursivas cujas regularidades implicam na produção de saberes positivos sobre o homem vivente, falante e trabalhador. Em Les mots et les choses (1966), o arqueólogo toma distância da relação do homem com sua verdade para privilegiar o jogo de regras qualificado como verdadeiro que permitiu no final do século XVIII a constituição ambígua do homem na condição de objeto de saber e sujeito de conhecimentos. Quando trata dos jogos de poder em torno da loucura e do crime, respectivamente nos livros Histoire de la folie à l'âge classique (1972) e Surveiller et punir (1975), busca saber como são constituídas determinadas práticas cujos efeitos implicam a produção de discursos verdadeiros sobre a razão alienada e sobre o caráter criminoso. A constituição do indivíduo louco e do indivíduo criminoso encontra-se atrelada às práticas sociais de aprisionamento e de encarceramento que, por sua vez, acarretam a produção de sujeições.

No presente estudo, busca-se destacar a articulação entre subjetividade e jogos de verdade estabelecida pelo pensador quando redireciona sua investigação para a cultura antiga greco-romana. Na primeira metade dos anos 1980 (Foucault falece em 1984), a articulação entre subjetividade e verdade adquire novos contornos e maior clareza no seu pensamento. Ao estudar as práticas ascéticas nas escolas filosóficas greco-romanas, Foucault observa nelas uma constituição do sujeito singular. Ele deixa de ser constituído somente na imanência de práticas que o sujeitam; ao mesmo tempo, torna-se sujeito e objeto para si próprio, denotando uma subjetivação ética irredutível aos mecanismos disciplinares e às regulações do biopoder das modernas sociedades ocidentais.

A articulação entre verdade e subjetividade configura a chave de releitura utilizada por Foucault em 1984, pouco antes de sua morte.

Através de quais jogos de verdade o homem se dá seu ser próprio a pensar quando se percebe como louco, quando se olha como doente, quando reflete sobre si como ser vivo, ser falante e ser trabalhador, quando ele se julga e se pune enquanto criminoso? Através de quais jogos de verdade o ser humano se reconheceu como homem de desejo? [Grifos nossos] (Foucault, 1984, p.13-4)

Essa retrospectiva inscreve-se no projeto amplo foucaultiano de uma história da verdade. A relação entre subjetividade e verdade evidencia-se 
ainda mais em sua investigação quando no curso L'herméneutique du sujet (2001) é desdobrada na diferença entre filosofia e espiritualidade, nas articulações entre cuidado de si e conhecimento de si, conhecimentos úteis e inúteis, cuidado de si e conversão a si, ascese e verdade.

\section{Filosofia e Espiritualidade}

Para Foucault, na filosofia moderna, cujo apogeu é o momento cartesiano, a articulação entre subjetividade e verdade prescinde da exigência ética. Moderna é "a forma de pensamento que se interroga sobre o que permite ao sujeito ter acesso à verdade, forma de pensamento que tenta determinar as condições e os limites do acesso do sujeito à verdade" (Foucault, 2001, p.16). Em tal maneira de filosofar, prescinde-se do modo de ser do sujeito, ao privilegiar as regras de formação do método ou a estrutura do objeto a ser conhecido. Considerada tal como ela é, a verdade não transforma o sujeito, na medida em que ele, tal como é, já é capaz de verdade.

Em contrapartida, a exigência ética é fundamental quando a subjetivação é adquirida mediante a ascese, constituindo objetivo maior da filosofia a transformação do modo de ser do sujeito. A exigência ética própria da articulação entre subjetividade e verdade é privilégio, ainda que não exclusivo, da filosofia antiga, particularmente entre estóicos e epicuristas. Seguindo os rastros de Pierre Hadot, que destaca a importância dos "exercícios espirituais" ${ }^{2}$ em tais filosofias, Foucault se refere a elas como "espiritualidade antiga". Esta designa "a busca, a prática, a experiência mediante as quais o sujeito opera sobre si próprio as transformações necessárias para ter acesso à verdade" (Foucault, 2001, p16), porquanto tal como ele é, não poderá adquiri-la. Segue-se que a modificação do modo de ser é fundamental para subjetivar discursos reconhecidos como verdadeiros. Os discursos (logói) são qualificados de verdadeiros se atuam como princípios e matrizes de ação, de modo a formar no indivíduo a atitude e a disposição necessárias para enfrentar os acontecimentos da existência.

Na espiritualidade antiga, a verdade, tal como ela é - no sentido de matriz de ações - pode transformar o sujeito na medida em que ele sempre é desqualificado para ser fundamento de verdade. Importante é ressaltar que alguém subjetiva discursos verdadeiros ao modo de conselhos para a ação ou de preparação adequada para as vicissitudes da existência. Ao mesmo tempo em que a ética do sujeito aponta os limites filosóficos do privilégio moderno do conhecimento de si, no qual o sujeito já é capaz de verdade, ela também qualifica os modos de aquisição antigos dos discursos verdadeiros mediante a ascese do cuidado consigo.

2 Ver o artigo "Exercices spirituels". In: HADOT, 2002b, p.19-74. 


\section{Cuidado de Si e Conhecimento de $\mathbf{S i}$}

Para Foucault, o fio condutor da articulação entre subjetividade e verdade é o cuidado de si. Engana-se quem pensa ser o sujeito constituído nas escolas filosóficas antigas somente pelo conhecimento de si. Tal percepção, corriqueira na filosofia e na psicologia contemporâneas, é alimentada de uma ilusão retrospectiva. Enfatiza Foucault que o conhecimento de si jamais é referência fundamental entre os antigos; ele é sempre referido ao princípio basilar do cuidado de si (epiméleia heautoû). Em que pese a conhecida afirmação de Epicteto de que o conhecimento de si está no centro da comunidade humana, ela deve ser minimizada porquanto é pronunciada numa época na qual a cidade de Delfos, onde se encontrava o templo de Apolo com a inscrição do gnôthi seautoû, é considerada o centro geográfico do mundo.

Michel Foucault acolhe a interpretação de Roscher (1901), ${ }^{3}$ segundo a qual o significado primeiro do preceito é desprovido de valor de fundamento moral. O "conhece-te a ti mesmo" faz parte de um conjunto de recomendações referente ao modo adequado pelo qual alguém deve se preparar para consultar o deus Apolo. Assim, é preciso evitar questões inúteis reduzindoas ao estritamente necessário, de onde o preceito "nada em demasia"; em seguida, é necessário prescindir de promessas que não se pode cumprir, de onde o conselho "comprometer-se traz infelicidade"; urge ainda examinar em si mesmo o que realmente é preciso saber, de onde o imperativo "conhece-te a ti mesmo".

Na filosofia, o imperativo "conhece-te a ti mesmo" surge em torno da figura de Sócrates. Em Defesa de Sócrates, Platão indica que conhecer a si mesmo constitui desdobramento do princípio do cuidado de si. A missão divina de Sócrates consiste em impelir os outros a se ocuparem de si mesmos, a terem cuidados consigo.

O solo da epiméleia heautoû, traduzido pelos latinos como cura sui e para o português como cuidado de si, diz respeito à atitude diferente consigo, com os outros e com o mundo; indica a conversão do olhar do exterior para o próprio interior como modo de exercer a vigilância contínua do que acontece nos pensamentos; sugere ações exercidas de si para consigo mediante as quais alguém tenta modificar-se; designa maneiras de ser, formas de reflexão e de práticas que conformam o núcleo da relação entre subjetividade e verdade.

3 (W.H. Roscher, "Weiteres über die Bedeutin des E [ggua] zu Delphi und die übrigen grammata Delphika", Philologus, 60, 1901, p.81-101), apud Foucault, 2001, p.5. 


\section{Conhecimentos úteis e inúteis}

O princípio do cuidado de si exige uma apropriação diferente do conhecimento. Nas suas relações com o mundo, com os outros e consigo o sujeito precisa privilegiar a modalidade de conhecimento que ajude na modificação de sua maneira de ser. A esse propósito, é de singular relevância a passagem do cínico Demetrius, citada por Sêneca no De Beneficiis e retomada por Michel Foucault em L'herméneutique du sujet (2001).

Demetrius ressalta que o bom atleta difere daquele que aprendeu todos os gestos possíveis ou encontra-se apto a executá-los na luta ou competição; antes, é o indivíduo que conhece gestos utilizados com freqüência, de modo que se lhe tornem suficientemente familiares e estejam à sua disposição quando a situação exigir.

Há conhecimentos inúteis que pertencem ao mundo exterior e existem conhecimentos úteis que concernem à existência humana (Foucault, 2001, p.222-3). Inútil é saber, por exemplo, as causas das coisas que a natureza esconde do homem, justamente porque é inútil sabê-las; caso contrário, a natureza as teria tornado visíveis. Em compensação, saber que há poucas situações em relação às quais o homem pode amedrontar-se, que nada há de se temer quanto aos deuses, que a morte produz mal algum, que é fácil encontrar o caminho da virtude e que alguém nasce para a comunidade, são conhecimentos extremamente úteis para o epicurista. Convém distinguir entre o saber das causas redutível ao conhecimento ornamental e, o saber relacional que vincula deuses, outros homens, coisas do mundo e esses seres que somos nós.

Entre os conhecimentos úteis ao homem, jamais é feita referência aos segredos da consciência e à busca da identidade do sujeito ou da natureza humana. Os segredos da natureza não dão lugar aos segredos da consciência. Trata-se sempre do mundo, dos outros, daquilo que os envolve. Possibilitar que o sujeito surja como elemento recorrente das relações é condição para olhar as coisas do mundo, os deuses e outros homens. Por conseguinte, a primeira modalidade de conhecimento útil é o saber relacional.

Outro aspecto dos conhecimentos úteis é que são transcritos mediante princípios de verdade, num duplo sentido: são ao mesmo tempo enunciados de verdade a partir dos quais outros podem ser deduzidos e preceitos de conduta diante dos quais é preciso submeter-se. Basta ao sujeito saber a respeito de suas relações com o mundo que o rodeia, de tal modo que aquilo normalmente constituído como verdade, passe a ser escutado, lido, memorizado e vivido como preceito.

Trata-se ainda de conhecimento que, uma vez adquirido, transforma o modo de ser do sujeito. Opõe-se ao conhecimento ornamental que, embora 
culturalmente considerado verdadeiro, não possui força prescritiva e conseqüentemente não modifica a maneira de ser de alguém.

Vale ressaltar que a diferença versa sobre o modo de ser do conhecimento e não sobre seu conteúdo. Deixa de ser importante a distinção entre as coisas do mundo e as da natureza humana. O conhecimento das causas e o ornamento da cultura apenas são designados de inúteis porque, na sua forma, são destituídos de pertinência prescritiva e não modificam o modo de ser. Em compensação, por conhecimentos úteis designam-se os saberes mediante os quais "aquilo que conhecemos sobre os deuses, os homens e o mundo, poderá ter efeito na natureza do sujeito, ou melhor dizendo, na sua maneira de agir, no seu êthos" (Foucault, 2001, p.227).

A subjetivação histórica do cuidado de si configura uma "ética do saber e da verdade" (Foucault, 2001, p.227). Nesse aspecto, os conhecimentos úteis ao homem têm caráter "etopoético" (Foucault, 2001, p.16). São capazes de produzir o êthos e modificar a maneira de ser de alguém. Jamais se referem à decifração pela consciência ou pela exegese de uma verdade escondida no interior do indivíduo.

No âmbito do governo de si e dos outros é incumbência do mestre saber utilizar como é preciso, das coisas verdadeiras que sabe, aquilo que é útil e eficaz para o trabalho de transformação de seu discípulo. Em vez de desvelamento da verdade, trata-se de prescrição de conduta e indicação daquilo que é necessário saber.

\section{Cuidado de Si e Conversão a Si}

A partir do momento que Michel Foucault estuda a subjetivação histórica do cuidado de si na filosofia helenística e romana, nos textos de Epicuro, Epicteto, Marco Aurélio e Sêneca, aponta para a ampliação do imperativo socrático. No estoicismo romano, o cuidado de si deixa de ser referido apenas à situação daquele que pretende governar em virtude de privilégio estatutário, tornando-se preceito que envolve a plenitude da existência.

A razão de ser do cuidado é irredutível ao déficit da pedagogia grega no final da adolescência; ela se refere à arte de viver (tékhne toû bíou) a ser desenvolvida ao longo da existência, desdobrando-se nas funções de luta, de crítica e de terapia.

Função de luta, porque o cuidado de si define-se como enfrentamento permanente diante dos acontecimentos e provações existenciais, para os quais é preciso dispor de armas adequadas (paraskeué). Longe de inculcar no sujeito habilidades técnicas ou profissionais, trata-se de prepará-lo de modo a suportar eventuais acidentes, infelicidades e desgraças que lhe possam ocorrer. 
Função de crítica, pois o cuidado de si exerce papel de correção. Seja lembrada a correção feita por Sócrates a Alcibíades, ao apontar nele a ignorância que ignora a si própria. Doravante, o cuidado de si impõe-se sobre o fundo dos erros, dos maus hábitos, das deformações e dependências incrustadas, das quais é preciso livrar-se. Em vez de "formação-saber", tratase de "correção-libertação" (Foucault, 2001, p.91).

Função terapêutica, posto que o cuidado de si assemelha-se à dietética, saber que conjuga cuidado do corpo e da alma. Se a medicina cura o páthos do corpo é tarefa da filosofia curar o páthos da alma. Plutarco, por exemplo, aglutina medicina e filosofia numa só região (mía khôra) (Foucault, 2001, p.94). Epicteto compara a escola de filosofia ao consultório médico (iatreîon) (Foucault, 2001, p.96). A permanente terapêutica do corpo e da alma converte-se em tarefa fundamental do cuidado de si, de modo a constituir-se o sujeito em médico de si próprio.

Dos deslocamentos do cuidado de si da cultura grega clássica para a cultura helenística e greco-romana, merece consideração sua passagem de privilégio estatutário de alguns, como o caso da situação peculiar de Alcibíades, para "princípio universal que se endereça e se impõe a todo mundo" (Foucault, 2001, p.108).

Seria inadequado, porém, afirmar que a partir do helenismo o princípio do cuidado de si converte-se em ética universal, porquanto sempre toma forma no interior de práticas, instituições, tais como escolas, fraternidades e seitas tão diferentes que, em alguns casos, até mesmo se excluem.

Na cultura greco-romana, o cuidado de si é universalizado como princípio e posto em prática de modo particularizado. Deixa-se de referir-se exclusivamente à excelência estatutária, pois todos são virtualmente capazes de exercê-lo, poucos são aqueles que efetivamente alcançam transformá-lo em atitude permanente. O critério de diferenciação está situado entre aqueles que escolhem o cuidado de si como modo de vida, e os demais, que não dedicam a ele tempo suficiente.

Malgrado isso, o cuidado de si está longe de ser privilégio aristocrático, tal é sua difusão nas camadas desfavorecidas da sociedade mediante grupos organizados em torno de cultos definidos e redes de amizade que prescrevem direitos e obrigações específicas. Um jogo é estabelecido entre um princípio universal que pode ser entendido e aplicado à vida pela escolha de alguns, de um lado, e o raro cuidado do qual ninguém a priori, se encontra excluído de outro (Foucault, 2001, p.115). Vale ressaltar que, doravante o princípio do cuidado de si emerge como fim privilegiado das práticas de si, sendo a conversão do olhar exigência fundamental.

Conversão do olhar difere de introspecção do sujeito. Ela está situada no vácuo nebuloso entre o eu ético e o sujeito inacabado. O percurso entre um e outro prescinde da distância que separa exterioridade e interioridade, nos 
termos do conhecimento do eu. Trata-se do interstício de obra artesanal permeado de inquietações e hesitações em que o sujeito procura um centro no qual fixar-se. "O que separa o eu ético do seu eu jamais completamente outro não deve ser medido em termos de conhecimento, mas de exercícios, de práticas, de ascese concreta. Do eu para o eu, separa-os apenas a tênue distância de uma obra a realizar, mas sempre inacabada" (Gros, 2003, p.163).

Conversão do olhar é conversão a si (conversio ad se). Diferentemente da metánoia cristã que exige renúncia permanente do eu, trata-se de renunciar ao entorno no qual vive o sujeito, somente quando as agitações exteriores impedem-no concentrar-se no seu objetivo. A conversão a si define-se como esquema prático: implica atos de proteção e de defesa, atitudes de respeito pelo eu, estado de alguém que está em posse do eu porque o domina.

A efetivação da conversão envolve a atenção detalhada (prosochè) quando se trata de distinguir entre aquilo que depende de nós e aquilo que não depende de nós. Atenção permanente sobre o eu precisa ser aplicada nas situações particulares da vida, de modo especial no instante presente. Ela ajuda o sujeito a desviar-se das paixões provocadas continuamente pelo saudosismo inútil sobre o passado ou pela ilusão a respeito do futuro e que independem de nós. Apenas o presente depende da ação livre do indivíduo, somente nas ações presentes ele constitui-se como sujeito. Além disso, a conversão a si toma distância da "trans-subjetivação" (Foucault, 2001, p.206) a partir da qual é estabelecida uma cesura essencial no sujeito; trata-se de processo longo e contínuo pelo qual alguém fixa a si próprio como objetivo mediante relações plenas consigo (Foucault, 2001, p.206). ${ }^{5}$

Efeito da conversão a si é a subjetivação da verdade pela qual alguém procura transformar seu modo de ser. Se a constituição da ética do sujeito é o objetivo almejado, importância significativa é atribuída aos exercícios permanentes exigidos do agente ético, de modo a considerá-lo apto a ser sujeito de verdades. A referência agora é o árduo percurso da ascese na cultura helenística e romana.

\section{Ascese e Verdade}

Na filosofia antiga, a ascese é condição de acesso à verdade. Verdade, no sentido etopoético, qual seja a qualificação de enunciados como verda-

\footnotetext{
4 Sobre a conversão cristã, no sentido de metánoia. Ver: Foucault, 2001, p.82, 172, 202, 206-209; Foucault, 1980, C 62 (08).

5 Sobre o questionamento da "relação plena consigo". Cf. Jaffro, 2003, p.51-79; 65-69.
} 
deiros quando atuam como matrizes de constituição do êthos do sujeito, de sua maneira de ser.

Michel Foucault aponta a ascese como critério de diferenciação entre espiritualidade antiga e filosofia moderna. Na espiritualidade antiga a ascese designa o penoso exercício do sujeito quando procura preencher a distância entre o eu e seu objetivo, entre o que deixou de ser e o que vem a se tornar. Difere, pois, do ascetismo cristão, ainda que semelhanças possam ser estabelecidas entre eles (Foucault, 1997, p.95).

Como ocorre no ascetismo cristão monástico, a ascese filosófica caracteriza-se pela austeridade; porém, suas táticas, meios e instrumentos objetivam a aquisição de algo que o sujeito ainda não possui, prescindindo da renúncia de si. Diante dos acontecimentos inesperados da vida, face à desgraça repentina, à irrupção da doença ou à sombra da morte iminente o sujeito se mune da armadura protetora, da "paraskeué" (Foucault, 2001, p.306). Se o cristão precisa de instrumentos de defesa para lutar contra as diversas tentações do maligno objetivando renunciar plenamente sua vontade e o mal que nela habita, o estóico precisa deles para fazer frente aos acontecimentos do mundo exterior. O cristão é o asceta de si mesmo enquanto o estóico é o asceta do acontecimento.

Na medida em que a ascese tem como fim adquirir a armadura necessária para enfrentar os acontecimentos da vida, tendo em vista que ela preenche a distância hesitante e inquieta entre o que se deixa de ser e o trabalho inacabado da transformação, trata-se de saber de que elementos tal armadura é constituída, como ela atua no indivíduo e quais técnicas ajudam na sua aquisição. A armadura protetora (paraskeué) é adquirida pelo indivíduo na escola filosófica quando subjetiva os discursos enunciados pelo mestre (lógoi). Não se tratam de axiomas e princípios de verdade em si mesmos, mas de enunciações materialmente pronunciadas e úteis ao sujeito. Bom asceta é aquele que conserva frases efetivamente escutadas ou lidas mediante a repetição, a rememoração e a escritura.

Para que as enunciações (lógoi) se transformem em armaduras do sujeito (paraskeué,) é necessário que sejam princípios aceitáveis de comportamento: só então são qualificadas de verdadeiras. Os lógoi precisam ser discursos persuasivos, porquanto não apenas formam convicções como também impregnam ações. Configuram esquemas indutores de ação: uma vez que habitem o pensamento, o coração e o corpo do sujeito agirão espontaneamente como se falassem em nome dele dizendo o que convém fazer e fazendo, efetivamente, o que é preciso fazer. Eles estão presentes no sujeito como matrizes de ação e é para adquiri-los que ele opta livremente pela ascese.

Adquirir tais matrizes de ação constitui o primeiro passo na seqüência do qual o sujeito precisa saber como preservá-las de modo a poder utilizá- 
las em qualquer momento. Elas constituem, assim, socorro indispensável diante dos acontecimentos.

Uma vez que o lógos fale, no momento em que o acontecimento se produz, uma vez que o lógos - que constitui a paraskeué - se formule para anunciar seu socorro, o socorro já está presente, dizendo-nos o que é preciso fazer, ou melhor, fazendo-nos fazer efetivamente o que devemos fazer. (Foucault, 2001, p.214)

Para que as matrizes razoáveis de ação sejam utilizáveis, precisam estar sempre "à mão" (prókheiron, em grego; ad manum, conforme a tradução latina) (Foucault, 2001, p.311). Plutarco observa sua presença no sujeito quando invoca algumas metáforas. A primeira delas é que os lógoi assemelham-se ao phármakon: comparam-se à medicação com a qual o sujeito precisa contar a fim de evitar adversidades e vicissitudes ao longo da existência. Outra é a de que os lógoi se parecem aos amigos: os verdadeiros lógoi são aqueles que exercem presença útil na adversidade, analogamente ao socorro que os verdadeiros amigos prestam ao sujeito quando deles mais precisa. Eles podem ser comparados, ainda, à voz interior que se faz ouvir quando as paixões iniciam suas agitações. Quando as vicissitudes chegam, as adversidades ameaçam e as paixões obstaculizam o equilíbrio próprio, os lógoi entram em ação de modo que o indivíduo aja como é conveniente. O efeito da atuação de tais matrizes de verdade é a constituição de sujeitos de ações. Por conseguinte, a ascese filosófica "é o que permite que o dizerverdadeiro - dizer-verdadeiro endereçado ao sujeito, dizer-verdadeiro que o sujeito endereça também a si mesmo - constitua-se como maneira de ser do sujeito. A áskesis faz do dizer-verdadeiro um modo de ser do sujeito" (Foucault, 2001, p.312).

No ascetismo cristão há o movimento de renúncia da vontade que resulta na objetivação do eu nas práticas de obediência; na ascese filosófica pretende-se adquirir a "subjetivação do discurso verdadeiro" (Foucault, 2001, p.317). Na primeira, a presença de tecnologias pastorais de extração e produção de verdade cujo efeito é a individualidade sujeitada; na segunda, a atuação de técnicas de si mediante as quais o acesso à verdade implica na transformação do sujeito.

Algumas das técnicas de si relevantes da áskesis dos primeiros séculos da era cristã são a escuta ativa e a escritura de si.

A técnica da escuta é indispensável para adquirir os lógoi. Plutarco declara que após o período de estudos, o sujeito precisa aprender a escutar o lógos durante o restante de sua vida adulta, porquanto a arte da escuta ajuda na distinção entre verdade e dissimulação. Ao invés do discípulo submeter-se ao controle do mestre sobre aquilo que deve ser escutado, ele precisa colocar-se na condição daquele que recolhe o lógos por meio da escuta. Daí 
ser fundamental o exercício da atenção (prosoché). A boa escuta exige que o auditor dirija sua atenção ao "tò prâgma", ao referente da palavra (Foucault, 2001, p.332). O referente da escuta filosófica é a enunciação verdadeira quando ela transforma-se em preceito de ação. A subjetivação da verdade supõe o movimento indissociável da enunciação do lógos e da pragmática da escuta.

Conforme recomenda Sêneca na Carta 108, endereçada a Lucílio, a escuta precisa ser ativa, de modo a transformar progressivamente a proposição ou asserção - regra que alguém usa não apenas para se conduzir, mas para viver e para guardá-la na alma - em preceito de ação. "A atenção filosófica é, portanto, aquela que se dirige a um prâgma, prâgma que é um referente, (...) que, na idéia, pode e deve se tornar preceito"(Foucault, 2001, p.333).

A boa escuta filosófica implica o direcionamento do olhar para o prâgma na sua significação filosófica, de modo que a enunciação valha como prescriÇão. Além disso, ela exige o olhar do sujeito sobre si mesmo de maneira que ao memorizar o que acaba de ouvir, tais discursos sejam subjetivados. Prestando atenção ao que escuta, ele não se desvia do referente. A enunciação verdadeira, que alguém memoriza, converte-se em seu discurso. Eis como a escuta constitui uma das técnicas fundamentais da subjetivação da enunciação verdadeira, sendo o escopo sempre renovado da ascese filosófica.

Além da escuta, a escritura constitui a técnica de si imprescindível da ascese. Ela objetiva a transformação dos discursos recebidos e reconhecidos como verdadeiros em princípios racionais da ação. Analogamente ao que ocorre com os saberes considerados úteis em oposição ao conhecimento ornamental, a escritura subjetiva, a verdade se for "etopoética" (Foucault, 1994, p.418), quando o lógos é transformado em êthos no sentido de princípio de ação. Tal é o que ocorre com os "hypomnémata" (Foucault, 1994, p.418-23) e as correspondências.

Os hypomnémata são cadernos individuais que servem como ajudamemória. Seu uso como livro de vida e guia de conduta é comum entre as pessoas cultas dos primeiros séculos de nossa era. Neles são escritas citações, fragmentos de obras, de exemplos e de ações que se viu, se leu ou se ouviu falar. Configuram a memória material das coisas lidas, entendidas e pensadas. Segue-se a necessidade de tê-los sempre à mão (ad manum) a fim de utilizá-los, caso haja necessidade. Tal técnica visa a constituição do lógos bioéthikos, conjunto de discursos úteis para situações vitais inusitadas enfrentadas pelo sujeito. A escritura, a releitura e a meditação de tais discursos possibilitam implantá-los progressivamente na alma como parte do próprio sujeito. Não se trata apenas da apropriação de discursos de verdade para torná-los seus, mas de constituir um eu por intermédio deles.

A correspondência é outra modalidade fundamental de escritura etopoética pela qual o processo de subjetivação ocorre em função da interação 
com os outros. A carta enviada a alguém age, pelo gesto mesmo da escritura, naquele que a escreve, como age ainda naquele que a recebe por meio da leitura e da releitura.

Exemplos de correspondência na filosofia estóica encontram-se novamente nas cartas de Sêneca a Lucílio, nas quais nota-se a direção espiritual do homem maduro, já retirado a outro homem jovem que ocupa importantes funções públicas. Nelas, além de comentar alguns princípios de conduta, Sêneca também ressalta "que é necessário exercitar-se por toda sua vida e que sempre há necessidade da ajuda de outrem na elaboração da alma sobre si própria" (Foucault, 2001, p.424). Na carta 7, o filósofo estóico detalha o trabalho que ele se impõe e em seguida sugere ao seu correspondente: "retirar-se em si mesmo tanto quanto possível; unir-se àqueles que são capazes de ter sobre si um efeito benéfico; abrir sua porta àqueles que têm esperança de se tornar melhores para si mesmos" (Sénèque, livre I, lettre $7, \S 8$, apud Foucault, 1994, p.424).

A correspondência vai além de mera técnica de si; ela constitui a maneira de exprimir-se e de expressar-se para si e para os outros; torna o remetente presente de forma quase imediata em relação ao destinatário. Ao mesmo tempo ela é "olhar que se estende ao destinatário (pela missiva que ele recebe, ele se sente olhado) e um modo de se apresentar ao seu olhar por aquilo que é dito de si mesmo" (Foucault, 1994, p.425). Tanto naquele que a remete, quanto naquele que a recebe, a correspondência implica introspecção, termo a ser aqui entendido como abertura interior ao destinatário.

Semelhante ao processo fisiológico da digestão a escritura converte-se em princípio de ação racional naquele que escreve. Inversamente, o escritor constitui sua subjetividade por intermédio do recolhimento das coisas ditas. Quando escreve, sua alma-sujeito se transforma. Assim como o ser humano carrega na fisionomia a semelhança natural de seus ancestrais, analogamente, naquilo que é escrito encontra-se a filiação dos pensamentos gravados na alma.

A problematização das diferentes técnicas de si da cultura antiga que atuam no processo de subjetivação da verdade constitui a "genealogia espiritual" proposta por Michel Foucault (1994, p.423). Na espiritualidade antiga, sobretudo no estoicismo, a prática ascética e suas múltiplas técnicas de si visam a subjetivação das enunciações verdadeiras por meio da transformação no modo de ser do sujeito ouvinte e escriturante. Fazer uso do equipamento adequado (paraskeué) para os acontecimentos da existência mediante enunciações verdadeiras (lógoi) é o objetivo da ascese estóica. Escutar ativamente e escrever constituem técnicas cujo propósito consiste em adquirir algo que ainda não se possui: matrizes práticas de ação.

A ascese filosófica produz subjetivações históricas em contínuo movimento, atribui atenção acentuada aos acontecimentos da existência e so- 
bre o modo como o indivíduo pode e deve preparar-se para enfrentá-los. A maneira privilegiada de tal preparação consiste na atenção às enunciações verdadeiras pronunciadas na relação pedagógica.

\section{O "Eu", Objeto de Cuidado}

Michel Foucault elabora a história das práticas ascéticas sem se propor descobrir a verdade no sujeito, situar na alma seu lugar ou fazer dela objeto de discurso. Práticas ascéticas visam armar o sujeito de esquemas pragmáticos e de princípios prescritivos. "Trata-se (...) de dotar o sujeito de uma verdade que ele não conhecia e que não residia nele; trata-se de fazer desta verdade aprendida, memorizada, progressivamente aplicada, um quase-sujeito que reina soberanamente em nós" (Foucault, 2001, p.481).

Nesse aspecto é que a subjetividade problematizada no último Foucault distancia-se das filosofias do sujeito. Dentre elas, a fenomenologia principalmente. Nesta corrente de pensamento o sujeito é supositum, cuja identidade é suficientemente firme para suportar, servir de fundamento, resistir à mudança. Em que pese as alterações de suas qualidades acidentais, o sujeito permanece o mesmo. Assim é que, desde Descartes o ego, do ego cogito, é o mais subjetivo dos sujeitos ao estar plenamente seguro de sua identidade.

Quando em L'herméneutique du sujet Foucault usa a expressão "quasesujeito" para caracterizar sua constituição entre os antigos, toma distância da perspectiva da fenomenologia. Em certa medida, a interpretação que faz de tal expressão não deixa de ser reflexo da própria maneira pela qual é postulada a sua própria ética do sujeito. "Quase-sujeito" convém ser compreendido como "alma-sujeito", tal como é encontrada no Primeiro Alcibíades, de Platão.

Foucault observa um paradoxo logo no início do diálogo do jovem Platão. Em que pese o subtítulo ser: "sobre a natureza humana", o eu objeto de cuidado afasta-se da pergunta pela própria natureza humana. Para começar, exige-se o cuidado do eu somente em função dos objetivos do governo sábio e justo: "qual o eu de que devo ocupar-me a fim de poder, como convém, ocupar-me com os outros a quem devo governar. É este círculo [que vai] do eu como objeto de cuidado ao saber do governo como governo dos outros que, creio, está no cerne deste final de diálogo" (Foucault, 2001, p.40).

Seja observada a diferença do ponto de partida adotado em relação ao diálogo República. Nesta, para definir a justiça individual, Platão investiga o que é a justiça na cidade. No Primeiro Alcibíades, para definir o que é o governo justo, interroga-se a alma individual como modelo para a cidade. A psyché designará, pois, o eu objeto de cuidado, protótipo para o justo governo dos outros. Para Foucault, Platão está distante da concepção de alma prisioneira do corpo, encontrada mais tarde no Fédon, no Fedro ou na Re- 
pública. Que o sujeito seja sua alma significa postulá-lo pragmaticamente como "sujeito de ação" (Foucault, 2001, p.55), que se serve dos órgãos corporais como instrumentos. Numa ampla acepção, servir-se (khrêstai) do eu (heautoû) designa a posição singular ocupada pela alma-sujeito (diferente da atribuição metafísica de alma-substância) em relação com o mundo, com os outros e consigo. Ocupar-se de si significa ser "sujeito de ações, de comportamentos, de relações, de atitudes" (Foucault, 2001, p.56-7). Tal é a tarefa que deve enfrentar Alcibíades, se quiser governar a cidade.

Não é o caso de delongar-se nos meandros do referido diálogo. Importa somente sublinhar a irredutibilidade da subjetivação ética proposta por Foucault pela leitura do texto platônico, comparado ao modo como o sujeito é compreendido pelas filosofias do sujeito. Reforça tal contraste a afirmação alhures de que desde o pensamento grego clássico até o helenismo grecoromano é impossível definir o sujeito, simplesmente porque ele inexiste, tal como a filosofia moderna o entende.

O que não quer dizer que os gregos não tenham se esforçado em definir as condições pelas quais seria dada uma experiência de si que não fosse aquela do sujeito, mas do indivíduo, na medida em que ele procura constituir-se como mestre de si. Faltava à Antigüidade clássica ter problematizado a constituição de si como sujeito; inversamente, a partir do cristianismo, houve uma confiscação da moral pela teoria do sujeito. (Foucault, 1994, p.706)

Como consideração final, seja ressaltado que essa hipótese levantada por Foucault não é insular. Ela poderia muito bem ser partilhada pelo eminente helenista recentemente falecido, Jean-Pierre Vernant. Esse pensador estabelece distinções significativas entre indivíduo, sujeito e ego, a propósito do estudo da filosofia antiga. Para ele, a história do indivíduo concerne ao "seu lugar e papel no seu grupo ou grupos, o valor a ele concedido, a margem de movimento que lhe é dada, sua autonomia relativa com respeito ao seu papel institucional." Quanto ao sujeito, dele é possível falar sempre que "o indivíduo usa a primeira pessoa para expressar-se e, ao falar em seu próprio nome, enuncia características que fazem dele um ser único." Por sua vez, o ego faz referência ao "conjunto das práticas e atitudes psicológicas que propiciam uma dimensão interior e um sentido de plenitude ao sujeito. Tais práticas e atitudes constituem-no como ser único, real e original cuja natureza autêntica reside inteiramente no segredo de sua vida interior" (Vernant, 1991, p.321).

Indivíduo, sujeito e ego correspondem a três gêneros literários: o indivíduo à biografia, o sujeito à autobiografia ou memória, o ego à confissão e ao diário. Conforme Vernant, ainda que os gregos tivessem produzido alguma forma de biografia ou autobiografia, não havia entre eles a confissão e o 
diário. Afora isso, o âmbito do indivíduo na autobiografia jamais designa a intimidade do eu. A psyché platônica é o daimon em nós, é "a alma em mim, e não minha alma" (Vernant, 1991, p.330). Essa é a razão pela qual a experiência grega do self não poderia ter dado origem ao cogito ergo sum, porquanto entre os gregos a psyché é irredutível ao ego psicológico.

Ainda se está distante da teoria do sujeito que, para Foucault, tem início quando emergem no Ocidente as práticas de confissão cristãs e, posteriormente, o processo racional da evidência do eu psicológico. Michel Foucault aponta que é possível na história da cultura ocidental delinear processos de subjetivação entre os quais o sujeito jamais é constituinte, mas sempre constituído para si e para os demais.

CANDIOTTO, Cesar. Subjectivity and truth in the late Foucault. Trans/Form/Ação, (São Paulo), v.31(1), 2008, p.87-103.

- ABSTRACT: The constitution of the subject in the investigation of the late Foucault is generally dealt with through the perspective of his aesthetics of existence. Such approach is mainly due to the reading of the two last volumes of The History of Sexuality (1984). However, the present article points out that in his Collège de France courses entitled Subjectivity and Truth (1981) and The Hermeneutics of the Subject (1982), a different reading can be elaborated. The relation between subjectivity and truth is evidently central in his thinking and its developments are presented from the differences established between philosophy and spirituality, from the articulations between care of the self and knowledge of the self, useful knowledge and useless knowledge, care of the self and conversion to the self, asceticism and truth.

- KEYWORDS: Subjectivity, Truth, Asceticism, Knowledge of the self, Care of the self.

\section{Referências bibliográficas}

FOUCAULT, M. Histoire de la folie à l'âge classique. Paris: Gallimard, 1972 (Coll. Tel). Histoire de la sexualité, II: L'usage des plaisirs. Paris: Gallimard, 1984 (Coll. Tel).

Surveiller et punir. Naissance de la prison. Paris: Gallimard, 1975 (Coll. Bibliothèque des Histoires).

Du gouvernement des vivants. Cours au Collège de France, 1979-1980.

Inédito. Disponível em fitas-cassete: C 62 (01-12). Arquivos IMEC, Paris, 1980.

Subjectivité et vérité. Cours au Collège de France, 1980-1981. Inédito. Disponível em fitas-cassete: C 63 (01-07). Arquivos IMEC, Paris, 1981.

L'Herméneutique du sujet. Cours au Collège de France, 1981-1982. Édition établie par François Ewald et Alessandro Fontana, par Frédéric Gros, Paris: Seuil/Gallimard, 2001 (Coll. Hautes études). 
FOUCAULT, M. Dits et écrits, IV. Édition établie sous la direction de Daniel Defert e François Ewald, avec la collaboration de Jacques Lagrange. Paris: Gallimard, 1994.

Discorso e verità nella Grecia antica. Edizione italiana a cura di Adelina Galeotti. Introduzione di Remo Bodei. Roma: Donzelli editore, 1997.

GROS, F. À propos de l'Herméneutique du sujet, In: BLANC, Guillaume le \& TERREL, Jean. Foucault au Collège de France: un itinéraire. Bordeaux: Presses Universitaires de Bordeaux (Coll. Histoire des pensées), 2003. p.149-63.

HADOT, P. Un dialogue interrompu avec Michel Foucault: Convergences et Divergences, In: ____. Exercices spirituels et philosophie antique. Nouvelle édition revue et augmentée. Paris: Albin Michel. 2002a. p.305-11.

Exercices spirituals, In: Exercices spirituels et philosophie antique. Nouvelle édition revue et augmentée. Paris: Albin Michel, 2002b. p.19-74.

JAFFRO, L. Foucault et le Stoïcisme: sur l'historiographie de L'herméneutique du sujet. In: GROS, Frédéric \& LÉVY, Carlos (Orgs.). Foucault et la philosophie antique. Paris: éditions Kimé, 2003. p.51-79.

VERNANT, J. -P. The individual within the City-State. In: Mortals and Immortals: Collected Essays. Princeton, NJ: Princeton University Press, 1991. 